\title{
The biology behind the human intervertebral disc and its endplates
}

\author{
K.A. Tomaszewski ${ }^{1}$, K. Saganiak ${ }^{1}$, T. Gładysz ${ }^{1}{ }^{2}$, J.A. Walocha ${ }^{1}$ \\ ${ }^{1}$ Department of Anatomy, Jagiellonian University Medical College, Krakow, Poland \\ ${ }^{2}$ Department of Oral Surgery, Jagiellonian University Medical College, Krakow, Poland
}

[Received 15 September 2014; Accepted 7 October 2014]

\begin{abstract}
The intervertebral discs (IVDs) are roughly cylindrical, fibrocartilaginous, articulating structures connecting the vertebral bodies, and allowing movement in the otherwise rigid anterior portion of the vertebral column. They also transfer loads and dissipate energy. Macroscopically the intervertebral disc can be divided into an outer annulus fibrosus surrounding a centrally located nucleus pulposus. The endplates surround the IVD from both the cranial and caudal ends, and separate them from the vertebral bodies and prevent the highly hydrated nucleus pulposus from bulging into the adjacent vertebrae. The IVD develop from the mesodermal notochord and receive nutrients mostly through the cartilaginous endplates. Physiologically they are innervated only in the outer annulus fibrosus by sensory and sympathetic perivascular nerve fibres, branches from the sinuvertebral nerve, the ventral rami of spinal nerves or from the grey rami communicantes. The IVD undergo changes with ageing and degeneration, the latter having two types i.e. "endplate-driven" involving endplate defects and inward collapse of the annulus fibrosus and "annulus-driven" involving a radial fissure and/or an IVD prolapse. This review summarises and updates the current state of knowledge on the embryology, structure, and biomechanics of the IVD and its endplates. To further translate this into a more clinical context this review also demonstrates the impact of ageing and degeneration on the above properties of both the IVD and its endplates. (Folia Morphol 2015; 74, 2: 157-168)
\end{abstract}

Key words: biomechanics, degeneration, disc degenerative disease, embryology, endplate, intervertebral disc

\section{INTRODUCTION}

The intervertebral discs (IVDs) are roughly cylindrical, fibrocartilaginous, articulating structures connecting the vertebral bodies, and allowing movement (flexion, extension, and rotation) in the otherwise rigid anterior portion of the vertebral column [63]. They are approximately 7 to $10 \mathrm{~mm}$ thick and $4 \mathrm{~cm}$ in diameter in the lumbar region of the spine [14], and constitute $1 / 3$ of the vertebral column's height [60]. The IVDs spread loading evenly on the verte- bral bodies, regardless of the position of the spine. Macroscopically the IVD can be divided into an outer annulus fibrosus (AF) surrounding a centrally located nucleus pulposus (NP) (Fig. 1). The endplates surround the IVDs from both the cranial and caudal ends, and separate them from the vertebral bodies and prevent the highly hydrated NP from bulging into the adjacent vertebrae. The endplates also absorb the considerable hydrostatic pressure that results from mechanical loading of the spine [64]. 


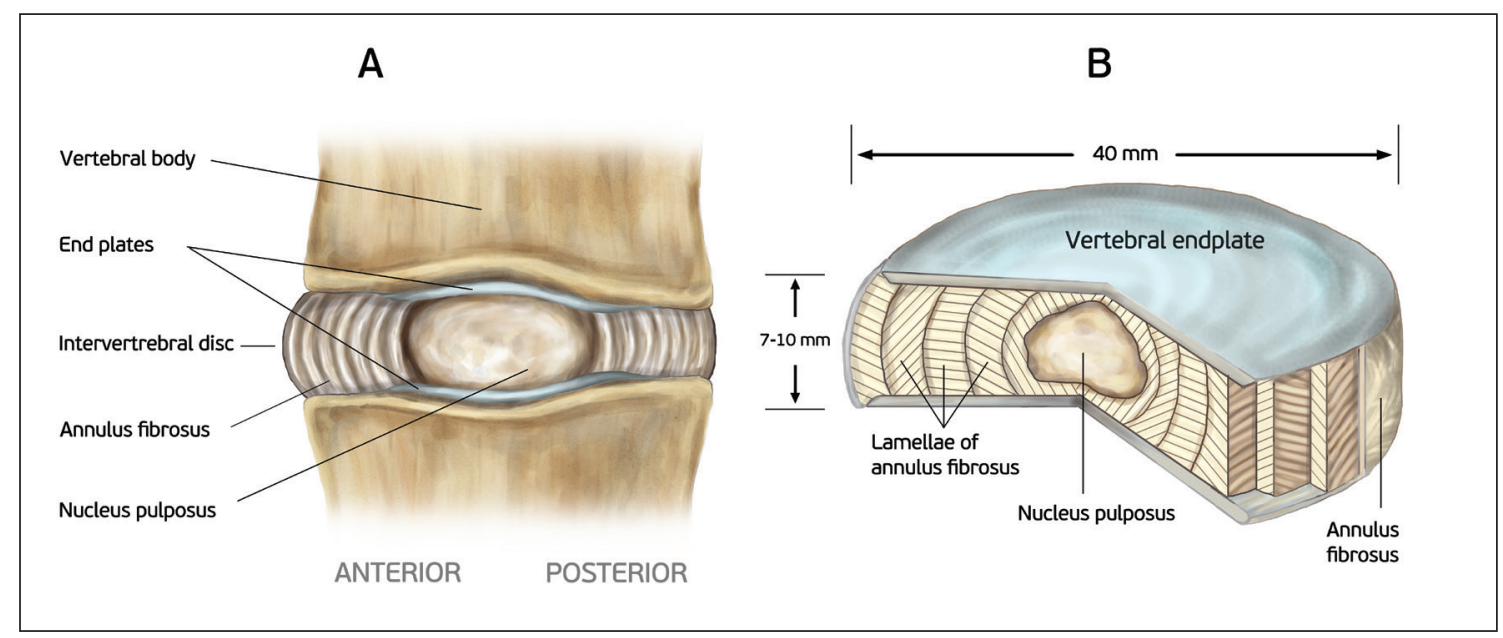

Figure 1. Location and structure of the human intervertebral disc on $(\mathbf{A})$ an axial section of the spine and $(\mathbf{B})$ on a cut out portion of the disc. Note the organisation of annulus fibrosus lamellae.

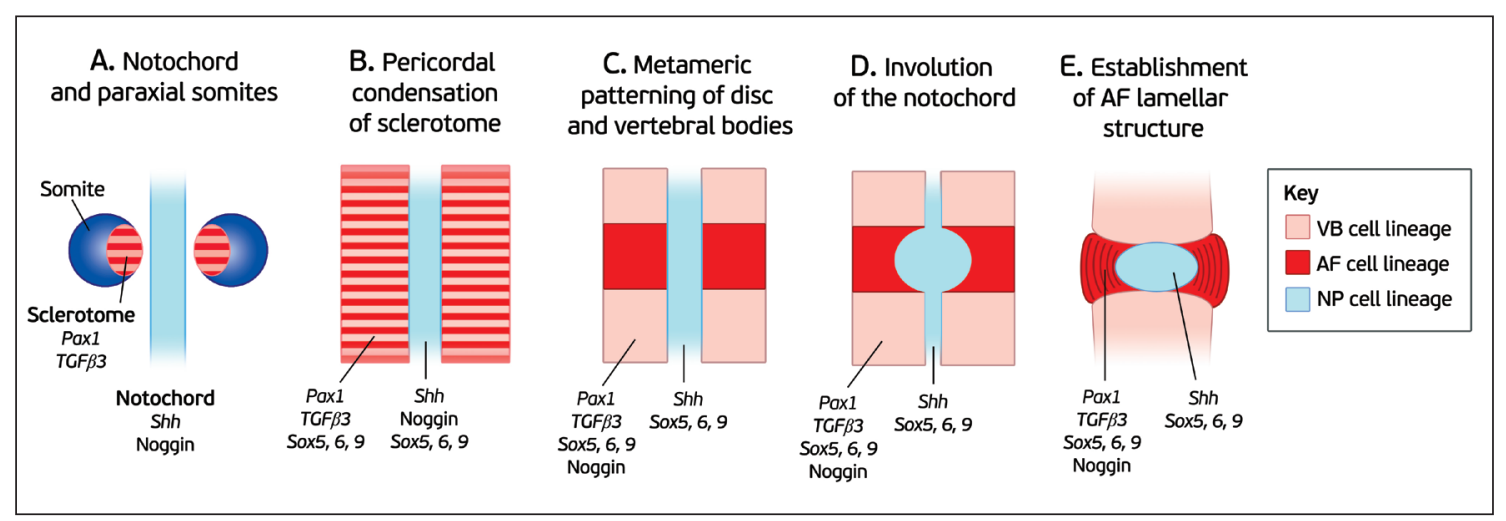

Figure 2. Schematic representation of embryonic morphogenesis of the mammalian intervertebral disc (IVD). Colours represent origins and fates of cell populations. Also indicated are key morphogens and transcriptional regulators implicated in the growth and differentiation of the disc structures at each developmental stage. A. The notochord adjacent to pairs of paraxial somites, which contain sclerotome cells; B. Sclerotome cells condense around the notochord; C. Cells adopt a metameric pattern of more condensed (red) and less condensed (pink) regions that give rise to the disc and vertebral bodies, respectively; $\mathbf{D}$. The notochord contracts within the vertebral body rudiments and expands within the future IVD to form the nucleus pulposus; $\mathbf{E}$. Basic structures of the disc are established, and annulus fibrosus (AF) cells adopt orientations and alignments that form the template for the lamellar structure; VB — vertebral body; NP — nucleus pulposus. Figure adapted from Smith et al. [72].

The aim of this review was to summarise and update the current state of knowledge on the embryology, structure, and biomechanics of the IVD and its endplates. To further translate this into a more clinical context this review demonstrates the impact of ageing and degeneration on the above properties of both the IVD and its endplates.

\section{THE DEVELOPMENT OF THE HUMAN INTERVERTEBRAL DISC}

The development of the vertebral column is centred around the mesodermal notochord [72, 75]. It both gives rise to the NP, as well as acts as a "signalling-centre" for cell migration, differentiation and survival $[18,72]$. The development of the IVD is depicted on Figure 2.

The two different parts of the IVD - the AF and the NP arise on two separate developmental pathways. At approximately 30 days human foetal gestation cells of the sclerotome migrate medially from pairs of paraxial somites to condense around the notochord (Fig. 2A, B) [37]. The metameric pattern of regions differing in the level of cell condensations gives rise to the AF (more condensed) and the vertebral bodies (less condensed) (Fig. 2C) [72]. Concurrently with AF morphogenesis, the notochord contracts within the forming vertebral body rudiments while simultaneously expanding within the intervertebral 
regions to form the NP (Fig. 2D) [9]. Simultaneously, cells in the future AF adopt a fibroblastic morphology, and mediated by cytoskeletal actin filaments align and orient to form the template for matrix deposition that later defines the AF angle-ply lamellar structure (Fig. 2E) [34]. Vertebrae ossification commences at the end of the $10^{\text {th }}$ week of gestation [71].

The main players in the molecular signalling of IVD embryogenesis are Sonic hedgehog (Shh), Noggin, Pax, Sox and transforming growth factor beta $(\mathrm{TGF} \beta)$. Shh is responsible for regulating skeletal morphogenesis by providing positional information and directing cell differentiation - leading to the definition of the sclerotome [24]. Noggin, expressed by notochordal cells [43], acts synergistically to Shh, and becomes localised to the developing AF where it remains until birth, potentially acting to block bone morphogenetic protein signalling that originates from the vertebral bodies [22].

Pax genes encode transcription factors that regulate proliferation, differentiation, apoptosis, cell migration and stem cell maintenance [72]. In particular, Pax expression is important for specifying and maintaining tissue boundaries [28], and as such might be responsible for delineating the more and less condensed regions of cells that will give rise to the IVDs and vertebral bodies, respectively [73]. Pax1 and Pax9 genes were specifically implicated in the development of the IVD, as in their absence, both IVDs and vertebral bodies fail to develop, being substituted by an irregular cartilaginous rod [59].

Among the Sox gene family Sox 5 , Sox 6 and Sox 9 are specifically implicated in chondrogenesis [68], and thus are important for IVD development. Sox 5 and Sox6 are expressed in both sclerotome-derived and notochordal cells [74]. Sox9 is expressed in all primordial cartilage during embryogenesis, coincident with collagen II expression, including in the sclerotome and notochord [10].

$\operatorname{TGF} \beta-3$ signalling is important for regulating cell proliferation and differentiation, and extracellular matrix production during skeletal development, with different TGF $\beta$-3 isoforms exhibiting tissue-specific expression profiles [46]. TGF $\beta$-3 has been shown to be strongly localised to the perichordal condensations that give rise to the AF and vertebral bodies. As condensation advances, this expression pattern becomes localised to the IVD anlagen, showing clear demarcation with respect to the adjacent vertebral bodies [58].

\section{STRUCTURE - ANATOMY, HISTOLOGY AND BIOCHEMISTRY OF THE INTER- VERTEBRAL DISC AND ITS ENDPLATES}

\section{Nucleus pulposus}

The centrally located NP consists of randomly arranged type II collagen fibres, and radially placed elastin fibres which are embedded in a highly hydrated aggrecan-containing gel [38]. The proteoglycan to collagen ratio is approximately 27:1 [19]. These large quantities of aggrecan located along chains of hyaluronan carry a fixed negative charge and generate an osmotic swelling pressure within the irregular meshwork of collagen type II fibrils [72]. Dispersed, at a low density (approximately $3000-5000 / \mathrm{mm}^{3}$ ) are chondrocyte-like cells $[41,60]$. At least two distinct cell phenotypes can be identified in the NP - notochordal cells (which disappear after the third year of life) [41], and chondrocyte-like cells - distinctly different from articular chondrocytes [47]. Recently Sakai et al. [67] described a third type of NP cells with properties similar to those of mesenchymal stem cells. However, due to their characteristics, these cells can be in fact notochordal cells [19].

Cells of the NP are highly specialised and survive in a very hypoxic environment $\left(1 \%\right.$ of $\mathrm{O}_{2}$ ). Hypoxia inducible transcription factors- 1 and -2 , that are key cellular regulators of the hypoxic response, were found to be constitutively active in NP cells [61]. This activity might be partly responsible for the large production of aggrecan by NP-resident cells, independent of oxygen conditions [5].

Recent studies have pointed out the importance of notochordal cells in the survival of chondrocyte-like cells. Erwin et al. [26] have shown that the secretome of notochordal cells had an anti-apoptotic effect on chondrocyte-like cells, through inhibition of apoptotic caspases-3 and -9 , and favoured the expression of aggrecan and type II collagen. Thus, the gradual disappearance of notochordal cells during skeletal maturation and aging constitutes a primary event initiating NP degeneration.

Outside the NP is the AF - the boundary between these two regions being very distinct in individuals $<10$ years of age [60].

\section{Annulus fibrosus}

The AF can be divided into two distinct areas the inner and the outer AF. The inner AF, which is also known as the transition zone, contains poorly organised extracellular matrix composed of type II 
collagen, proteoglycans, and water. In contrast, the outer AF is highly organised and is rich in type I collagen, with undetectable levels of type II collagen and proteoglycans, and higher resistance to tension [19].

A typical lumbar AF is made up of 15-25 concentric lamellae, with type I collagen fibres passing obliquely (at approximately $60^{\circ}$ to the vertical axis) between vertebral bodies, with orientation of the fibres being reversed in successive lamellae (Fig. 1B) [42] (however type Il collagen can also be produced by AF cells) [17]. These lamellae originate as individual discrete bundles of collagen fibres, but their organisation becomes increasingly complex with more bifurcation and interdigitations as the individual ages, and the lamellae increase in thickness [42]. Elastin fibres, constituting $2 \%$ of the AF dry weight, pass radially from one lamella to the next, binding them together, and possibly helping the IVD return to its original arrangement following bending [91]. Additionally, the lamellae are interconnected by lubricin and type VI collagen $[45,70]$. Lubricin, known for its lubricant role within diarthrodial joints, is probably involved in the reduction of friction between adjacent lamellae.

The morphology of AF cells (approximately 9000 cells $/ \mathrm{mm}^{3}$ ) changes from the outer to the inner part, from thin, elongated (parallel to the collagen fibres) and fibroblast-like to more oval, respectively. AF cells, similar to NP cells, can have several long, thin cytoplasmic projections, which may be more than $30 \mathrm{~mm}$ long. The function of these projections remains unknown, but it is speculated that they act as sensors of mechanical strain within the tissue [25].

\section{Endplates}

Each IVD is bordered at the cranial and caudal ends by endplates which separate the vertebral bone from the IVD itself (Fig. 3) and prevent the highly hydrated nucleus from bulging into the adjacent vertebrae. They are identifiable from an early embryological stage and possess an osseous as well as a hyaline cartilage component [78]. The endplates are usually less than $1 \mathrm{~mm}$ thick (thinner in the centre than on the outside) and composed of hyaline cartilage [60]. Type II collagen fibres within the endplate run horizontal and parallel to the vertebral bodies, with the fibres continuing into the IVD (Fig. 3) [64]. Additionally, type X collagen is thought to be the most important in the endplate since it is a marker of hypertrophic chondrocytes and is involved in calcification [6].

Proteoglycan molecules within the endplate matrix are necessary for the control of solute transport

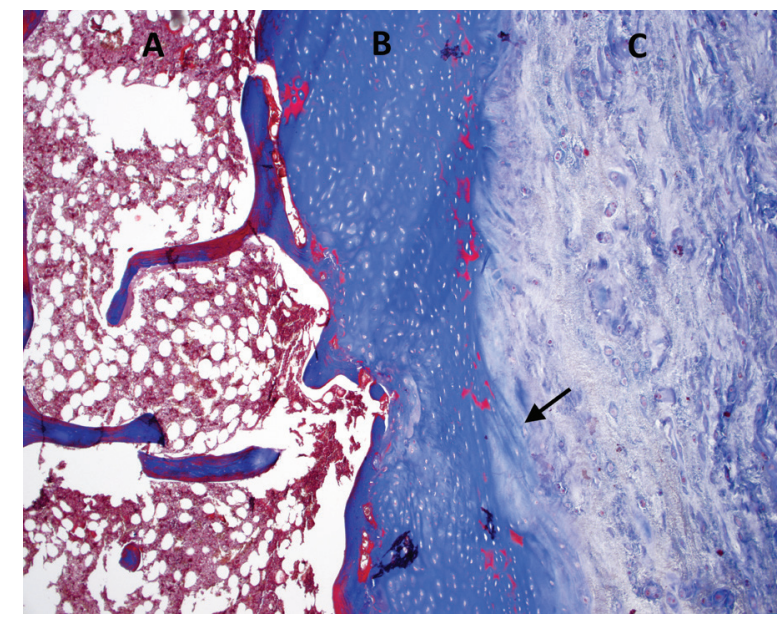

Figure 3. Histological slide (midsagittal section at the level of the nucleus pulposus) showing vertebral bone marrow (A), cartilaginous endplate (B), nucleus pulposus (C). The arrow points to endplate fibres continuing into the intervertebral disc. Red colour in the region of the endplate represents calcifications. Masson-Goldner trichrome staining, magnification $200 \times$.

and maintenance of water content throughout the IVD. Depletion of proteoglycans from the endplate cartilage is associated with loss of proteoglycans from the NP [65]. This translates further that proteoglycan loss would ultimately lead to degeneration of the IVD [56]. Alterations in IVD biochemistry, particularly in the endplate, during the skeletal growth may also be involved in the development of scoliosis [7].

In regards to cell type only chondrocytes constitute the endplates, and produce an extracellular matrix rich in type II collagen and proteoglycans (1:2 ratio - similar to articular cartilage), with water content of 50-60\% [64].

The endplates also contain a network of microscopic blood vessels that are responsible for nutritional intake during development and growth of IVDs (Fig. 4A). Metabolites diffuse through pores present in the growth plates based on their size and charge. Only positive ions (e.g., sodium, calcium) or neutral molecules, such as glucose and oxygen, can diffuse [65]. The network mostly involutes around the time of skeletal maturity [31].

\section{VASCULAR SUPPLY AND NUTRITION OF THE INTERVERTEBRAL DISC AND ITS ENDPLATES}

Blood with nutrients reaches the IVD through external (present around the outer AF) and endplate capillaries that are branches of segmental arteries, 


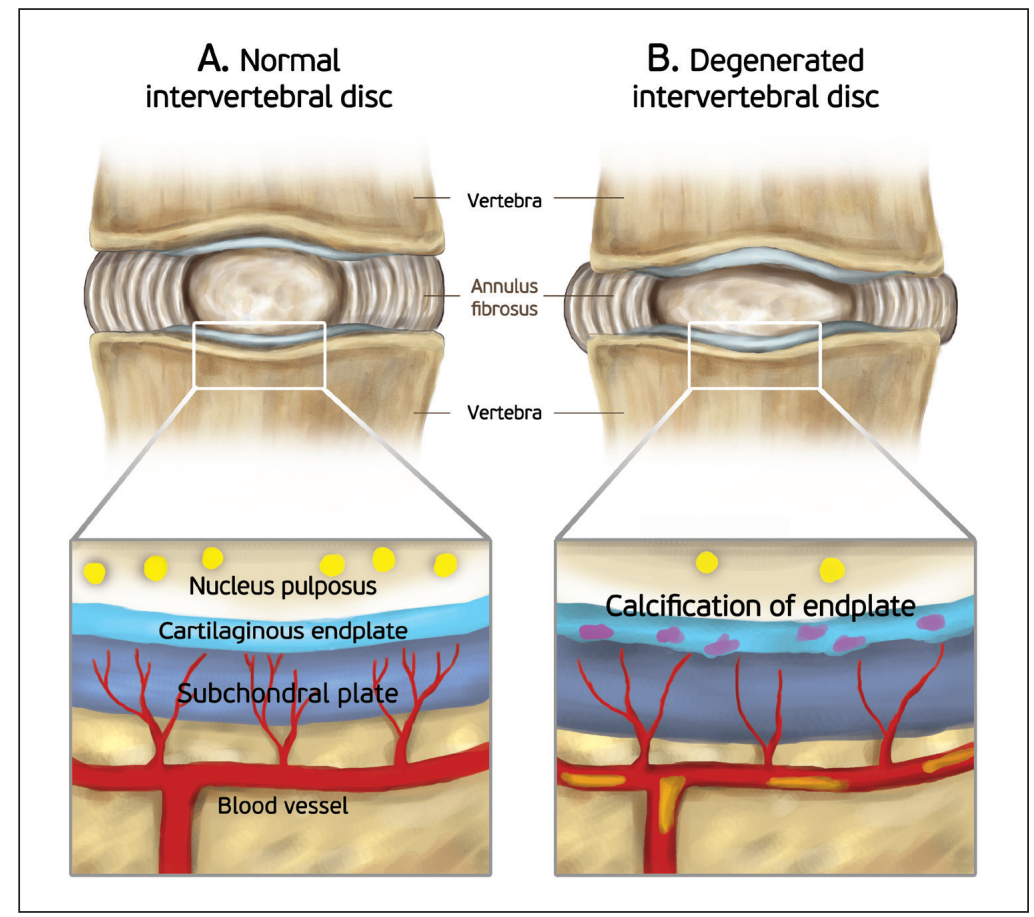

Figure 4. Changes in intervertebral disc (IVD) and endplate structure due to endplate calcification, fall in nutrient transport and resulting degeneration; A. Normal IVD - note the high number of patent blood vessels penetrating the endplate but not entering into the disc, and the high number of nucleus pulposus cells; B. Degenerated IVD — note the presence of calcifications in the blood vessels, a fall in their number, as well as calcification of the endplate, and a fall in the number of nucleus pulposus cells.

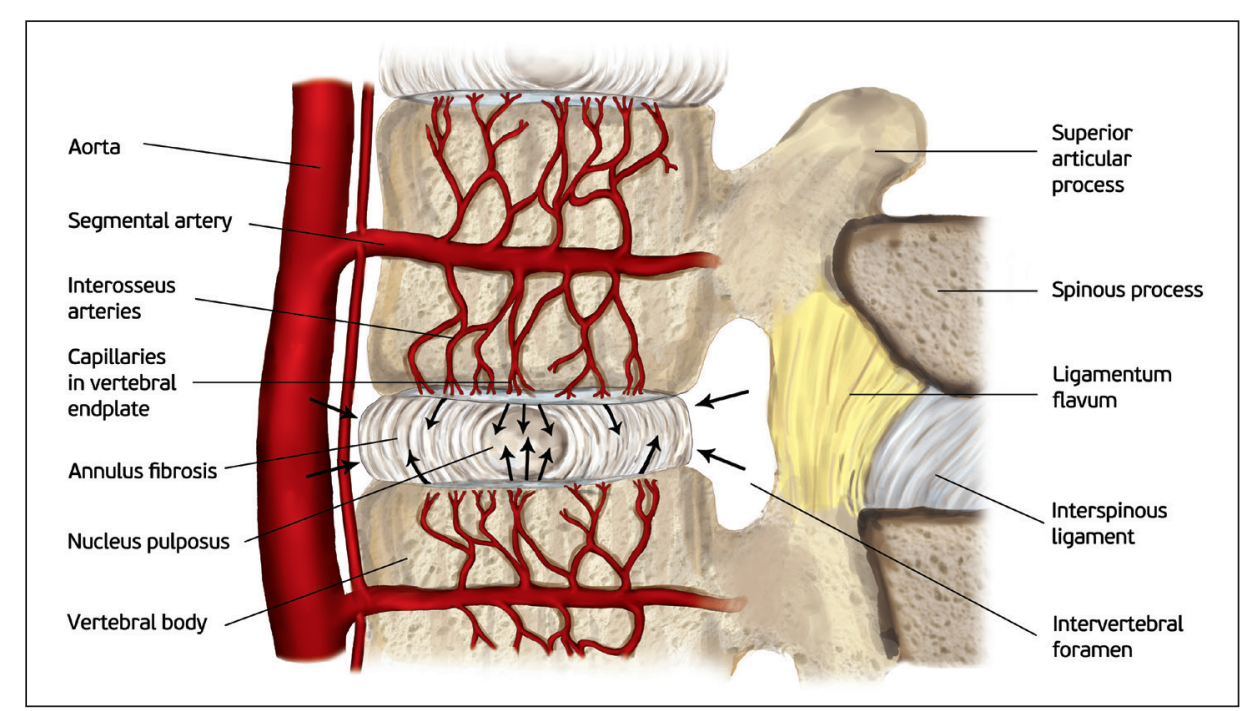

Figure 5. Physiological routes of nutrient supply to the intervertebral disc (IVD). The arrows point to the routes via which nutrients are delivered to the IVD - via the endplates as well as through the outer annulus fibrosus (in both cases nutrients are delivered through diffusion).

which in turn branch off the aorta (Fig. 5) [60]. The blood drains to the subchondral venous network or into the veins of the marrow spaces of the vertebral bodies [21]. Blood flow in the region of the endplates is not entirely passive - muscarinic receptors have been identified, and they can probably influence disc nutrition under altered physiological conditions [86].
The IVD is the largest avascular structure in the human body, with some cells being up to $8 \mathrm{~mm}$ from the nearest direct blood supply [82]. Essential nutrients (e.g. oxygen, glucose, amino acids etc.) are supplied to the IVD from its peripheries (Fig. 5). Metabolic waste products are removed from the IVD via a reverse route [35]. This causes variations in both 
oxygen concentration and $\mathrm{pH}$ throughout the different zones of the IVD [35]. Low oxygen tension in the centre of the IVD leads to anaerobic metabolism, resulting in a high concentration of lactic acid and low $\mathrm{pH}$ [82]. In vitro experiments show that a chronic lack of oxygen causes NP cells to become quiescent, while a chronic lack of glucose leads to their death [36].

In vitro studies using small dye molecules have demonstrated that the lateral margins of the endplate near the vertebral rim are relatively impermeable compared with the central portion or the entire AF [49]. It was shown that endplate permeability is caused by microscopic blood vessels, ending in capillary buds (loop-like structures), that penetrate the endplate via marrow contact channels $[12,49]$. It is through this route that the majority (approximately $80 \%$ ) of nutrients are transported to the IVD [43]. However, diffusion from the capillary buds to the IVD is purely dependent on the size and ionic charge of the molecules involved. The net negative charge of the NP conferred by the high concentration of proteoglycans permits passage of positive ions such as sodium and calcium and uncharged molecules such as glucose and oxygen, while impeding movement of negatively charged ions such as sulphate and chloride and macromolecules such as immunoglobulins and enzymes $[35,48]$.

In humans, during the early postnatal years, blood vessels that have penetrated the AF and cartilage endplates, from as early as 35 weeks gestation, begin to recede, eventually leaving the IVD as a completely avascular structure [50], with only a low number of vessels present in the endplate. Possible reasons for vascular regression include decreased nutrient requirements following the initial period of rapid growth or, more likely, the inability of the circulatory pressure to compete with large physiological stresses in the surrounding extracellular matrix [72]. What is more, the paths that the blood vessels followed never fully remodel and leave translamellar bridging elements [45], whose function is as of yet unknown. Probably they respond to radial and shear deformations [72]. However, it is unclear whether this influence would assist or impair the function of the IVD. In the foetus and in infants, the subchondral plate is also penetrated by regularly spaced nutrient canals similar to those seen in other growth cartilages [89]. These disappear in childhood, leaving residual "weak spots" that may later lead to Schmorl node formation and even later, to sclerosis of the subchondral plate [16].

\section{INNERVATION OF THE INTERVERTEBRAL DISC}

Under physiological conditions the human IVD is poorly innervated - only by sensory and sympathetic perivascular nerve fibres, found mostly in the outer zone of the AF, accompanying blood vessels or travelling independently $[29,60]$. Most of the fibres innervating the IVD are nociceptive, and to a lesser extent proprioceptive. A small number of mechanoreceptors are also present in the IVD in its 2-3 outer AF lamellae, most commonly having the morphology of Golgi tendon organs, a few Ruffini receptors, and even fewer Pacinian corpuscles [62]. The adult vertebral endplate is fully aneural [57].

The IVD is innervated by branches of the sinuvertebral nerve, by nerves derived from the ventral rami of spinal nerves or by nerves derived from the grey rami communicantes [77]. Intervertebral discs also receive innervation from two dense nerve interconnected plexuses located in the anterior and posterior longitudinal ligaments (Fig. 6) [30, 76]. It is agreed that lumbar IVDs are innervated segmentarily [8]. The innervating fibres arise primarily from small dorsal root ganglions which are classified based on their stimulus-response function and also based on their neurochemistry and connectivity [29].

Healthy IVDs are innervated only in the region of the external lamellae of the $\operatorname{AF}$ (Fig. 7A) $[29,57,77,90]$. The fibres responsible for this innervation pattern can be either associated with blood vessels or travel independently, and are positive for substances such as acetylcholinesterase, neurofilament protein, substance $P$, calcitonin gene-related peptide, vasoactive intestinal polypeptide, neuropeptide $Y$, C-flanking peptide and synaptophysin $[20,55]$.

With progressive IVD degeneration the nerves grow into the inner part of the $A F$, and sometimes even to the NP. These are mostly nociceptive fibres that may accompany ingrowing blood vessels (Fig. 7B). The immunohistochemical profile of nerve fibres and neurons innervating pathological IVDs is identical to that reported in normal conditions. Thus, the differences in the pattern of IVD innervation in normal conditions in comparison with degenerated conditions are quantitative rather than qualitative [20, $44,77]$. Additionally, together with the hyperinnervation of the IVD, there is increased nerve growth factor expression [40], as well as an increase in the 


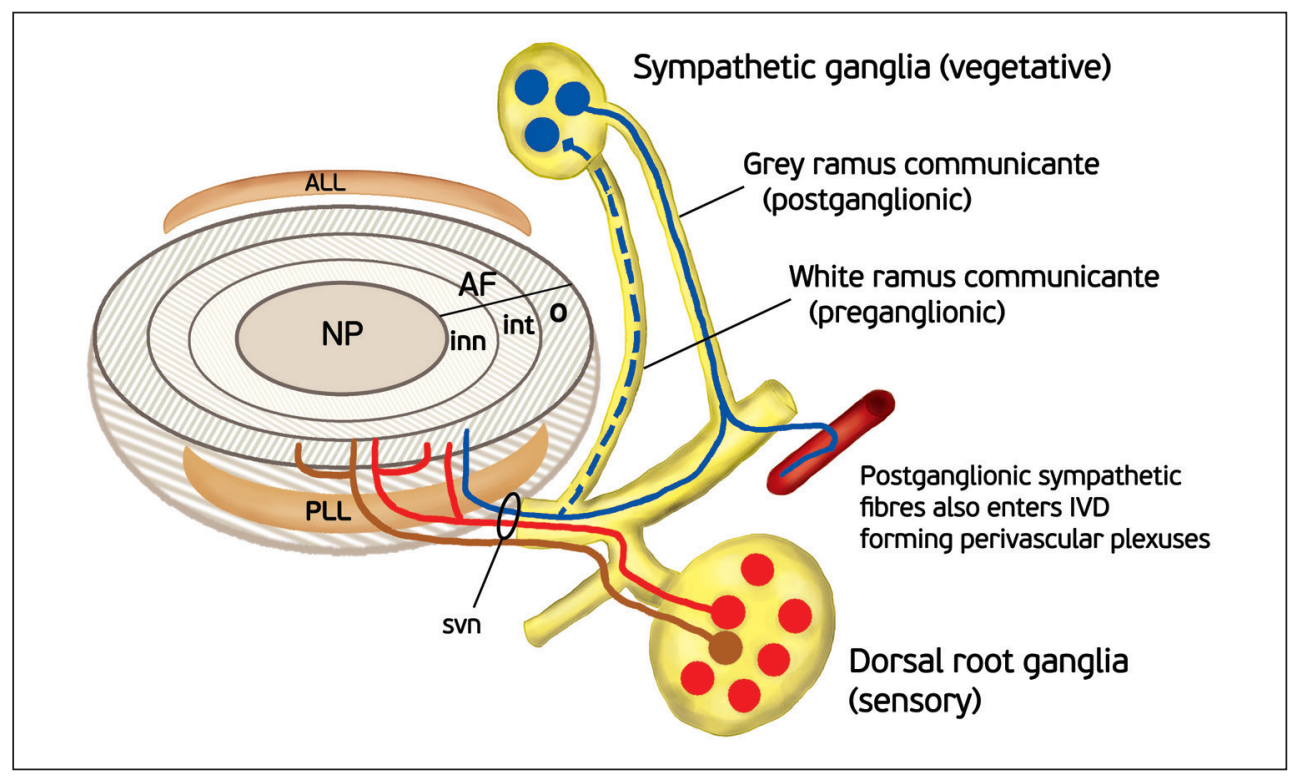

Figure 6. Schematic representation of the innervation of the intervertebral disc (IVD). Nociceptive sensory fibres originating in the dorsal root ganglia (red) and postganglionic sensory nerve fibres (blue) enter the outer part of the annulus fibrosus. Nerves in the IVD arise from the sinuvertebral nerve, from spinal nerves or from grey rami communicantes. In addition, mechanical nerve fibres originate in the dorsal root ganglia and coming from the anterior and posterior longitudinal ligament innervate the external layers of the annulus fibrosus of the IVD; ALL — anterior longitudinal ligament; PLL — posterior longitudinal ligament; NP — nucleus pulposus; AF — annulus fibrosus; inn — inner; int — intermediate; 0 — outer; svn — sinuvertebral nerve. Figure adapted from García-Cosamalón et al. [29].

number of Golgi-tendon organ-like structures such as Ruffini's and Pacinian corpuscles [20,62]. There is also evidence that sympathetic afferents are also increased in degenerating IVDs and that they play a significant role in lower back pain [29].

\section{BIOMECHANICS OF THE INTERVERTEBRAL DISC AND ITS ENDPLATE}

The most important function of the IVD is mechanical - to transfer loads, dissipate energy, and allow movement in the vertebral column. Both the NP and AF act synergistically to distribute and transmit loads between the vertebral bodies [51]. During compression hydrostatic pressure is generated within the NP which is constrained peripherally by the AF. In turn in the lamellar structure of the AF circumferential tensile stresses are generated [51]. The NP has a high water content (because of aggrecan which has a high anionic glycosaminoglycan content and provides appropriate osmotic properties [87]), which makes it act almost like fluid. This entire "compression-coping" mechanism is additionally supported by the inner AF, which is rich in proteoglycans (Fig. 8) [85]. The angle-ply structure and nonlinear properties of the AF facilitate joint mobility and stability in multiple modalities, including bending, rotation, and combinations of both $[32,69]$.
With increasing age, IVD water content decreases, especially in the NP. Most of the AF then acts like a fibrous solid band to resist compression directly. In physically disrupted discs, regions of fibrous tissue resist mechanical loading in a haphazard manner, and the hydrostatic balance of the NP is reduced or absent [4].

The endplates also have to be noted for their ability to absorb the considerable hydrostatic pressure that results from mechanical loading of the spine [48].

\section{INTERVERTEBRAL DISC AGEING AND DEGENERATION}

To begin with, the most important thing is to distinguish between physiological ageing, healing and remodelling and pathological degeneration of the IVD and its endplate. Adams and Roughely [4] proposed a definition of IVD degeneration, based on IVD loss of structural integrity - "excessive mechanical loading causes an IVD to degenerate by disrupting its structure and precipitating a cascade of nonreversible cell-mediated responses leading to further disruption. A degenerated IVD is one with structural failure combined with accelerated or advanced signs of aging.".

The following sections will review the basic changes related to IVD and endplate ageing and degeneration. 


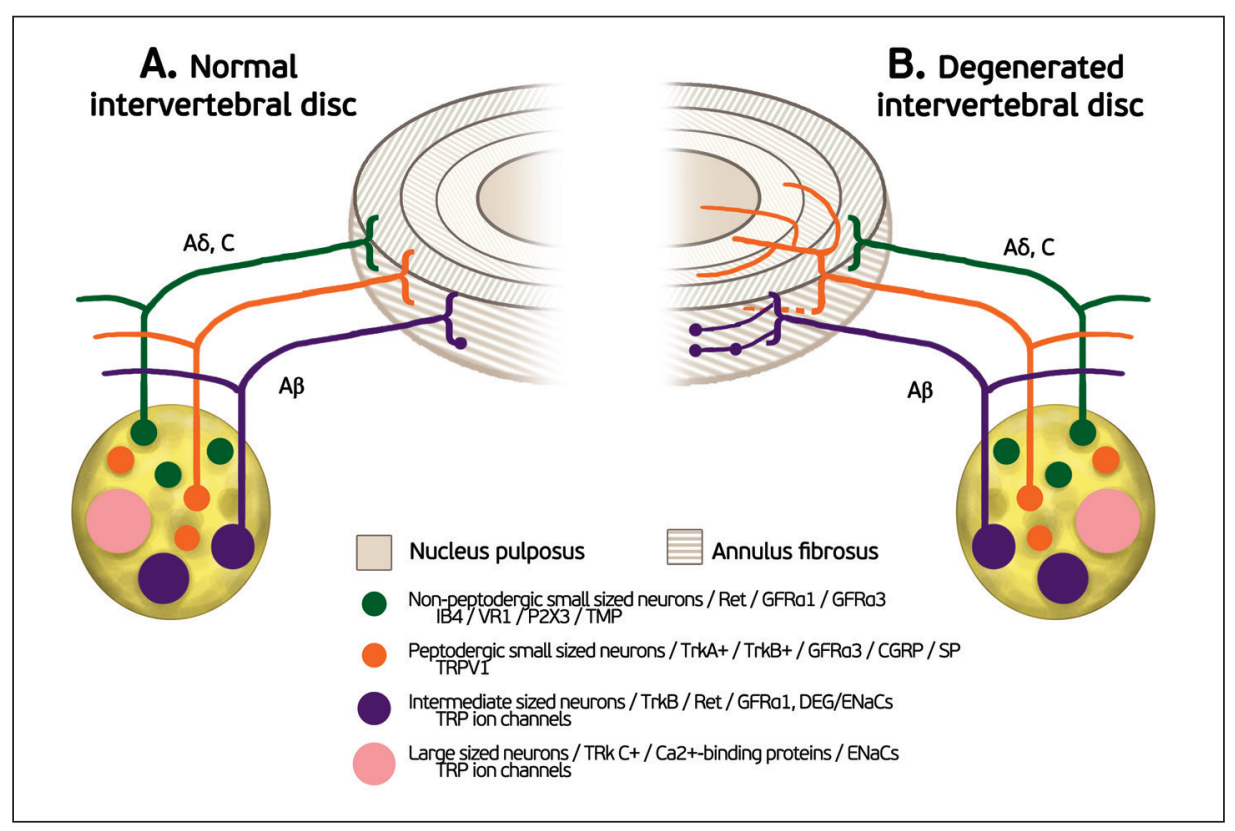

Figure 7. Schematic representation of the innervation of normal (A) and degenerated (B) intervertebral discs (IVDs), as well as the origin of sensory nerve fibres that innervate them. In the normal IVD, innervation is restricted to the outer layers of the annulus fibrosus and consists of small nerve fibres (orange and green) and some large fibres forming mechanoreceptors (purple). In the degenerated IVD, nerve fibres are higher in number and they enter the inner layers of the annulus fibrosus and even the nucleus pulposus. Furthermore, in these conditions, the densities of mechanoreceptors in the superficial layers of IVD are increased. Dorsal root ganglia contain different types of sensory neurons that project to the IVD and to the dorsal horn of the spinal cord. Thin myelinated $A \delta$ fibers and unmyelinated $C$ fibers arise from small neurons (orange and green), which, in the spinal cord, synapse in lamina I and II and mediate nociception. The myelinated A $\beta$ fibers (purple) arise from intermediate neurons. At the periphery they form slowly and rapidly adapting low-threshold mechanoreceptors, and synapse in lamina III and IV in the dorsal horn of the spinal cord. They mediate sensations of touch, pressure and vibration. Most of the sensory nerve fibers innervating the IVD are $A \delta$ or $C$ fibers. They originate from small peptidergic neurons expressing TrkA/TrkB (the receptor for nerve growth factor/brain-derived neurotrophic factor; orange) or non-peptidergic neurons expressing the common signalling receptor for glial cell-derived neurotrophic factor family of neurotrophic factors (Ret) (orange). Neurons in dorsal root ganglia can be differentiated based on their pattern of expression of receptors for neurotrophic factors, pattern of expression of different ion channels primarily of the degenerin/epithelial sodium channels (DEG/ /ENaCs) (ENaCa, b and c; acid-sensing ion channel (ASIC)1, ASIC2 and ASIC3) and transient receptor potential (TRP) (TRPA1, TRPC1, TRPC6 and TRPV1-4) families, and peptide content; CGRP — calcitonin gene-related peptide; GFRa1 and GFRa3 — glial cell-line-derived neurotrophic receptor subtypes a1 and a3; P2X3 — ATP-gated ion channel subtype P2X3; SP — substance P; TMP — thiamine monophosphatase; VR1 — vanilloid receptor subtype 1. Figure adapted from García-Cosamalón et al. [29].

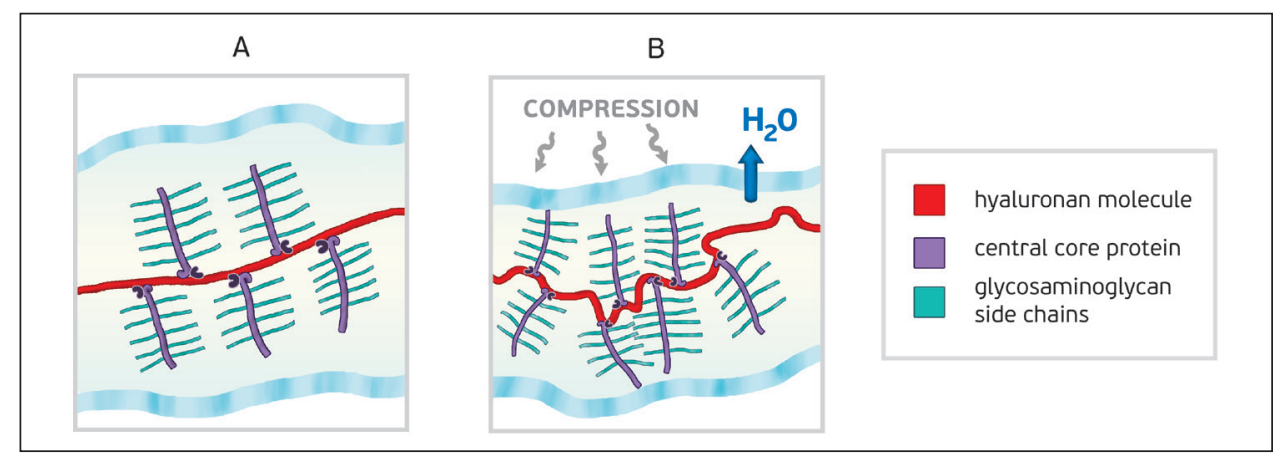

Figure 8. Intervertebral disc (IVD) "compression-coping" mechanisms. The nucleus pulposus is depicted as containing proteoglycan aggregates entrapped in a collagen fibre network. Proteoglycan aggregates are depicted as a central hyaluronan molecule (red) substituted with aggrecan molecules possessing a central core protein (purple) and sulphated glycosaminoglycan side chains (light green); A. State of equilibrium - nucleus pulposus is rich in water due to the high anionic glycosaminoglycan content. This is balanced by tensile forces in the collagen network; B. Compressive forces transmitted through the spine to the IVD lead to part of the water being forced out of the IVD. This increases aggrecan concentration and subsequently IVD swelling potential, thus resisting further compression. On removal of the compressive load, disc height is restored as water is drawn back into the tissue to restore the original equilibrium conditions. Any parameter that decreases proteoglycan concentration or weakens the collagen network will be detrimental to disc function. 


\section{Ageing of the intervertebral disc}

During growth and skeletal maturation, the boundary between the AF and the NP becomes less obvious, and with increasing age the NP generally becomes more fibrotic and less gel-like [15]. The NP tends to condense into several fibrous lumps, separated from each other and from the cartilage endplate by softer material [4]. Proteoglycan fragmentation starts during childhood [15] and with increasing age, the overall proteoglycan and water content of the IVD decreases, especially in the NP [4]. In turn, the collagen content increases, with type I collagen replacing type II, and the AF "engulfing" the NP, and making the IVD stiffer [4]. Interestingly, as long as the detached proteoglycans remain inside the IVD (encapsulated by the AF and the endplates), they still fulfil a functional role similar to that of the intact proteoglycans [2]. Reduced matrix turnover in older discs enables collagen molecules and fibrils to become increasingly cross-linked with each other, and existing cross-links become more stable [23].

Since early childhood, the blood supply to the IVD and the endplate decreases [13], together with cell density [41], leading to an increased incidence of structural defects - mostly in the AF [4]. Changes progress gradually, affecting first the endplates, then the NP, and finally the AF [13]. However, these changes might simply reflect the necessary adaptations to increased mechanical loading at the onset of ambulation, and reduced metabolite transport in a growing IVD.

The microstructural clefts and tears that appear increasingly during growth may possibly lead to more extensive disruption in later life, but so long as they remain small, they appear to have little effect on the internal mechanical function of the IVD [3].

As mentioned earlier, with increasing age, the hydrostatic NP becomes smaller and decompressed. Thus more of the compressive load-bearing is taken by the AF [4]. Disc height does not show a major decrease with age [27], although degenerative changes can cause the AF to collapse in older IVDs [4].

It is also important to distinguish simple injury from IVD degeneration. AF tears are not remodelled as in bone, presumably because the sparse cell population is unable to break down the large collagen fibre bundles of the AF and replace them with new ones [66]. Collagen turnover time in articular cartilage is approximately 100 years [83] and could be even longer in the IVD. Proteoglycan turnover is faster, possibly 20 years [66]. Injuries that affect the inner AF or the endplate decompress the NP [81] and healing processes are then overtaken by severe degenerative changes [4]. It is important to note that age-related IVD changes are not associated with pain [11].

\section{Degeneration of the intervertebral disc}

Adams and Dolan [1] have brought to light that there exist two distinct types of IVD degeneration - "endplate-driven" involving endplate defects and inward collapse of the AF and "annulus-driven" involving a radial fissure and/or an IVD prolapse. The structural defects which initiate the two processes both act to decompress the NP, making it less likely that the other defect could occur subsequently. The first type of IVD degeneration is characterised by high heritability, mostly affects IVDs in the upper lumbar and thoracic spine, often starts to develop before 30 years of age, usually leads to moderate back pain, and is associated with compressive injuries. The second type has a low heritability, mostly affects IVDs in the lower lumbar spine, develops progressively after 30 years of age, usually leads to severe back pain and sciatica, and is associated with repetitive bending and lifting.

Individual genes associated with IVD degeneration include those for type IX collagen, aggrecan, vitamin $\mathrm{D}$ receptor, alkaline phosphatase, matrix metalloproteinase (MMP)-3, and cartilage intermediate layer protein $[1,4,39,54,80,84]$. The products of these genes probably affect the strength of skeletal tissues, and their systemic effects may explain why IVD degeneration is more prevalent in those with osteoarthritis [33].

\section{Endplate changes with ageing and degeneration}

With ageing the cartilaginous part of the endplate diminishes in thickness and undergoes remodelling, leading to cartilage calcification or formation of true bone [52]. Which of the two actually occur remains unresolved. This process impedes nutrient transport via the endplate contact channels $[12,79]$, not only by physically obstructing them but also through blood vessel occlusion (Fig. 4B) [48]. It has been shown, both in vitro and in vivo, that calcification found in scoliotic IVDs can impede transport of even small molecules [65, 82].

In some cases the endplate undergoes revascularisation - in response to both physiological [53] and pathological stimuli [48]. The creation of blood vessels in the endplate occurs by activation of MMPs 
which are normally maintained in latent form by tissue inhibitors [88].

Morphological changes are also present in the endplates in association with IVD degeneration, and include fissures and clefts along the length of the endplate in the horizontal plane with occasional chondrocyte death [48].

\section{CONCLUSIONS}

The IVD together with its endplates forms an apparently simple structure, which at a closer look reveals its complexity - largely still unknown to us. Though recent years have brought about considerable research advancements in the field of IVD degeneration, we are still not yet sure where ageing ends and degeneration begins. However, there are multiple reasons to be optimistic, as new insights into the process of IVD and endplate degeneration are made every day, and we are always ever closer to unravelling the mysteries of back pain.

\section{ACKNOWLEDGEMENTS}

This study was funded by the National Science Centre, Poland under grant number DEC-2012/07/N/ /NZ5/00078. Krzysztof A. Tomaszewski received a scholarship to prepare his PhD thesis from the National Science Centre, Poland under award number DEC-2013/08/T/NZ5/00020.

\section{AUTHOR CONTRIBUTION}

Design and planning of the study - KAT, TG, JAW. Bibliographic search - KAT, KS, TG. Drafting and revising the manuscript - KAT. Preparing figures - KS. Obtaining funding - KAT. Critical revision of the manuscript - JAW. All authors have read and approved the final version of the manuscript.

All co-authors confirm the above-mentioned contributions and consent to the fact that this study is a part of Krzysztof A. Tomaszewski PhD thesis. The co-authors confirm that Krzysztof A. Tomaszewski has contributed significantly ( $80 \%$ in total) to every part of this study, as stated above.

\section{REFERENCES}

1. Adams MA, Dolan P (2012) Intervertebral disc degeneration: evidence for two distinct phenotypes. J Anat, 221: 497-506.

2. Adams MA, Freeman BJ, Morrison HP, Nelson IW, Dolan P (2000) Mechanical initiation of intervertebral disc degeneration. Spine, 25: 1625-1636.

3. Adams MA, McNally DS, Dolan P (1996) 'Stress' distributions inside intervertebral discs. The effects of age and degeneration. J Bone Joint Surg Br, 78: 965-972.
4. Adams MA, Roughley PJ (2006) What is intervertebral disc degeneration, and what causes it? Spine (Phila Pa 1976), 31: 2151-2161.

5. Agrawal A, Guttapalli A, Narayan S, Albert TJ, Shapiro IM, Risbud MV (2007) Normoxic stabilization of HIF-1alpha drives glycolytic metabolism and regulates aggrecan gene expression in nucleus pulposus cells of the rat intervertebral disk. Am J Physiol Cell Physiol, 293: 621-631.

6. Aigner T, Gresk-otter KR, Fairbank JC, von der Mark K, Urban JP (1998) Variation with age in the pattern of type $X$ collagen expression in normal and scoliotic human intervertebral discs. Calcif Tissue Int, 63: 263-268.

7. Antoniou J, Arlet V, Goswami T, Aebi M, Alini M (2001) Elevated synthetic activity in the convex side of scoliotic intervertebral discs and endplates compared with normal tissues. Spine, 26: 198-206.

8. Aoki Y, Ohtori S, Takahashi $\mathrm{K}$, Ino H, TakahashiY, Chiba T, Moriya H (2004) Innervation of the lumbar intervertebral disc by nerve growth factor-dependent neurons related to inflammatory pain. Spine, 29: 1077-1081.

9. Aszodi A, Chan D, Hunziker E, Bateman JF, Fassler R (1998) Collagen II is essential for the removal of the notochord and the formation of intervertebral discs. J, Cell Biol, 143, 1399-1412.

10. Barrionuevo F, Taketo MM, Scherer G, Kispert A (2006) Sox9 is required for notochord maintenance in mice. Dev Biol, 295: 128-140.

11. Battie MC, Videman T, Parent E (2004) Lumbar disc degeneration: epidemiology and genetic influences. Spine, 29: 2679-2690.

12. Benneker LM, Heini PF, Alini M, Anderson SE, Ito K (2005) 2004 Young Investigator Award Winner: vertebral endplate marrow contact channel occlusions and intervertebral disc degeneration. Spine (Phila Pa 1976), 30: 167-173.

13. Boos N, Weissbach S, Rohrbach H, Weiler C, Spratt KF, Nerlich AG (2002) Classification of age-related changes in lumbar intervertebral discs: 2002 Volvo Award in basic science. Spine, 27: 2631-2644.

14. Broberg KB (1983) On the mechanical behaviour of intervertebral discs. Spine, 8: 151-165.

15. Buckwalter JA (1995) Aging and degeneration of the human intervertebral disc. Spine, 20: 1307-1314.

16. Chandraraj S, Briggs CA, Opeskin K (1998) Disc herniations in the young and end-plate vascularity. Clin Anat, 11: 171-176.

17. Chelberg MK, Banks GM, Geiger DF, Oegema TR Jr (1995) Identification of heterogeneous cell populations in normal human intervertebral disc. J Anat, 186: 43-53.

18. Choi KS, Cohn MJ, Harfe BD (2008) Identification of nucleus pulposus precursor cells and notochordal remnants in the mouse: implications for disk degeneration and chordoma formation. Dev Dyn, 237: 3953-3958.

19. Colombier P, Clouet J, Hamel O, Lescaudron L, Guicheux J (2014) The lumbar intervertebral disc: from embryonic development to degeneration. Joint Bone Spine, 81: 125-129.

20. Coppes MH, Marani E, Thomeer RT, Groen GJ (1997) Innervation of "painful" lumbar discs. Spine, 22: 2342-2349.

21. Crock HV, Goldwasser M (1984) Anatomic studies of the circulation in the region of the verterbal end-plate in adult greyhound dogs, Spine, 9: 702-706.

22. DiPaola CP, Farmer JC, Manova K, Niswander LA (2005) Molecular signaling in intervertebral disk development. J Orthop Res. 23: 1112-1119. 
23. Duance VC, Crean JK, Sims TJ, Avery N, Smith S, Menage J, Eisenstein SM, Roberts S (1998) Changes in collagen cross-linking in degenerative disc disease and scoliosis. Spine 23: 2545-2551.

24. Ehlen HW, Buelens LA, Vortkamp A (2006). Hedgehog signaling in skeletal development. Birth Defects Res C Embryo Today, 78: 267-279.

25. Errington RJ, Puustjarvi K, White IR, Roberts S, Urban JP (1998) Characterisation of cytoplasm-filled processes in cells of the intervertebral disc. J Anat, 192: 369-378.

26. Erwin WM, Islam D, Inman RD, Fehlings MG, Tsui FW (2011) Notochordal cells protect nucleus pulposus cells from degradation and apoptosis: implications for the mechanisms of intervertebral disc degeneration. Arthritis Res Ther, 13: R215.

27. Frobin W, Brinckmann P, Biggemann M, Tillotson M, Burton K (1997) Precision measurement of disc height, vertebral height and sagittal plane displacement from lateral radiographic views of the lumbar spine. Clin Biomech (Bristol, Avon), 12: S1-S63.

28. Frost V, Grocott T, Eccles MR, Chantry A (2008) Self-regulated Pax gene expression and modulation by the TGFbeta superfamily. Crit Rev Biochem Mol Biol, 43: 371-391.

29. García-Cosamalón J, del Valle ME, Calavia MG, García-Suárez O, López-Muñiz A, Otero J, Vega JA (2010) Intervertebral disc, sensory nerves and neurotrophins: who is who in discogenic pain? J Anat, 217: 1-15.

30. Groen GJ, Baljet B, Drukker J (1990) Nerves and nerve plexuses of the human vertebral column. Am J Anat, 188: 282-296.

31. Grunhagen T, Wilde G, Soukane DM, Shirazi-Adl SA, Urban JP (2006) Nutrient supply and intervertebral disc metabolism. J Bone Joint Surg, 88: 30-35.

32. Guerin HL, Elliott DM (2007) Quantifying the contributions of structure to annulus fibrosus mechanical function using a nonlinear, anisotropic, hyperelastic model. J Orthop Res, 25: 508-516.

33. Hassett G, Hart DJ, Manek NJ, Doyle DV, Spector TD (2003) Risk factors for progression of lumbar spine disc degeneration: the Chingford Study. Arthritis Rheum, 48: 3112-3117.

34. Hayes AJ, Benjamin M, Ralphs JR (1999) Role of actin stress fibres in the development of the intervertebral disc: cytoskeletal control of extracellular matrix assembly. Dev Dyn, 215: 179-189.

35. Holm S, Maroudas A, Urban JP, Selstam G, Nachemson A (1981) Nutrition of the intervertebral disc: solute transport and metabolism. Connect Tissue Res, 8: 101-119.

36. Horner HA, Urban JP (2001) 2001 Volvo Award Winner in Basic Science Studies: Effect of nutrient supply on the viability of cells from the nucleus pulposus of the intervertebral disc. Spine, 26: 2543-2549.

37. Hunter CJ, Matyas JR, Duncan NA (2003) The notochordal cell in the nucleus pulposus: a review in the context of tissue engineering. Tissue Eng, 9: 667-677.

38. Inoue $H$ (1981) Three-dimensional architecture of lumbar intervertebral discs. Spine, 6: 139-146.

39. Kawaguchi $Y$, Osada R, Kanamori M, Ishihara H, Ohmori K, Matsui H, Kimura T (1999) Association between an aggrecan gene polymorphism and lumbar disc degeneration. Spine, 24, 2456-2460.

40. Kokubo Y, Uchida K, Kobayashi S, Yayama T, Sato R, Nakajima H, Takamura T, Mwaka E, Orwotho N, Bangirana A, Baba H (2008) Herniated and spondylotic intervertebral discs of the human cervical spine: histological and immunohistological findings in 500 en bloc surgical samples. Laboratory investigation. J Neurosurg Spine, 9: 285-295.

41. Liebscher T, Haefeli M, Wuertz K, Nerlich AG, Boos N (2011) Age-related variation in cell density of human lumbar intervertebral disc. Spine (Phila Pa 1976), 36: 153-159.

42. Marchand F, Ahmed AM (1990) Investigation of the laminate structure of lumbar disc annulus fibrosus. Spine, 15: 402-410.

43. McMahon JA, Takada S, Zimmerman LB, Fan CM, Harland RM, McMahon AP (1998) Noggin-mediated antagonism of BMP signaling is required for growth and patterning of the neural tube and somite. Genes Dev, 12: 1438-1452.

44. Melrose J, Roberts S, Smith S, Menage J, Ghosh P (2002) Increased nerve and blood vessel ingrowth associated with proteoglycan depletion in an ovine anular lesion model of experimental disc degeneration. Spine, 27: 1278-1285.

45. Melrose J, Smith SM, Appleyard RC, Little CB (2008) Aggrecan: versican and type $\mathrm{VI}$ collagen are components of annular translamellar crossbridges in the intervertebral disc. Eur Spine J, 17: 314-324.

46. Millan FA, Denhez F, Kondaiah P, Akhurst RJ (1991) Embryonic gene expression patterns of TGF beta 1 , beta 2 and beta 3 suggest different developmental functions in vivo. Development, 111: 131-143.

47. Minogue BM, Richardson SM, Zeef LA, Freemont AJ, Hoyland JA (2010) Characterization of the human nucleus pulposus cell phenotype and evaluation of novel marker gene expression to define adult stem cell differentiation. Arthritis Rheum, 62: 3695-3705.

48. Moore RJ (2006) The vertebral endplate: disc degeneration, disc regeneration. Eur Spine J, Suppl 3: S333-\$337.

49. Nachemson A, Lewin T, Maroudas A, Freeman MAR (1970) In vitro diffusion of dye through the endplate and the annulus fibrosus of human intervertebral discs. Acta Orthop Scand, 41: 589-607.

50. Nerlich AG, Schaaf R, Walchli B, Boos N (2007) Temporo-spatial distribution of blood vessels in human lumbar intervertebral discs. Eur Spine J, 16: 547-555.

51. O'Connell GD, Johannessen W, Vresilovic EJ, Elliott DM (2007) Human internal disc strains in axial compression measured noninvasively using magnetic resonance imaging. Spine, 32 : 2860-2868.

52. Oda J, Tanaka H, Tsuzuki N (1988) Intervertebral disc changes with aging of human cervical vertebra from the neonate to the eighties. Spine, 13: 1205-1211.

53. Oki S, Matsuda Y, Shibata T, Okumura H, Desaki J (1996) Morphologic differences of the vascular buds in the vertebral endplate-scanning electron microscopic study. Spine, 21: 174-177.

54. Paassilta P, Lohiniva J, Göring HH, Perälä M, Räinä SS, Karppinen J, Hakala M, Palm T, Kröger H, Kaitila I, Vanharanta H, Ott J, Ala-Kokko $L$ (2001) Identification of a novel common genetic risk factor for lumbar disk disease. JAMA 285: 1843-1849.

55. Palmgren T, Grönblad M, Virri J, Kääpä E, Karaharju E (1999) An immunohistochemical study of nerve structures in the annulus fibrosus of human normal lumbar intervertebral discs. Spine, 24: 2075-2079.

56. Pearce RH, Grimmer BJ, Adams ME (1987) Degeneration and the chemical composition of the human intervertebral disc. J Orthop Res, 5: 198-205.

57. Pederson HE, Blunck CFJ, Gardner E (1956) The anatomy of lumbosacral posterior rami and meningeal branches of spinal 
nerves (sinu-vertebral nerves): with an experimental study of their functions. J Bone Joint Surg Am 38-A: 377-391.

58. Pelton RW, Dickinson ME, Moses HL, Hogan BL (1990) In situ hybridization analysis of TGF beta 3 RNA expression during mouse development: comparative studies with TGF beta 1 and beta 2. Development, 110: 609-620.

59. Peters H, Wilm B, Sakai N, Imai K, Maas R, Balling R (1999) Pax1 and Pax9 synergistically regulate vertebral column development. Development, 126: 5399-5408.

60. Raj PP (2008) Intervertebral disc: anatomy-physiology-pathophysiology-treatment. Pain Pract, 8: 18-44.

61. Rajpurohit R, Risbud MV, Ducheyne P, Vresilovic EJ, Shapiro IM (2002) Phenotypic characteristics of the nucleus pulposus: expression of hypoxia inducing factor-1, glucose transporter-1 and MMP-2. Cell Tissue Res, 308: 401-407.

62. Roberts S, Eisenstein SM, Menage J, Evans EH, Ashton IK (1995) Mechanoreceptors in intervertebral discs. Spine, 20: 2645-2651.

63. Roberts S, Evans H, Trivedi J, Menage J (2006) Histology and pathology of the human intervertebral disc. J Bone Joint Surg Am, 88: 10-14.

64. Roberts S, Menage J, Urban JPG (1989) Biochemical and structural properties of the cartilage end-plate and its relation to the intervertebral disc. Spine, 14, 166-174.

65. Roberts S, Urban JP, Evans H, Eisenstein SM (1996) Transport properties of the human cartilage endplate in relation to its composition and calcification. Spine, 21: 415-420.

66. Roughley PJ (2004) Biology of intervertebral disc aging and degeneration: Involvement of the extracellular matrix. Spine, 29: 2691-2699.

67. Sakai D, Nakamura Y, Nakai T, Mishima T, Kato S, Grad S, Alini M, Risbud MV, Chan D, Cheah KS, Yamamura K, Masuda K, Okano H, Ando K, Mochida J (2012) Exhaustion of nucleus pulposus progenitor cells with ageing and degeneration of the intervertebral disc. Nat Commun, 3: 1264.

68. Schepers GE, Teasdale RD, Koopman P (2002) Twenty pairs of sox: extent, homology, and nomenclature of the mouse and human sox transcription factor gene families. Dev Cell, 3: 167-170.

69. Schmidt H, Kettler A, Heuer F, Simon U, Claes L, Wilke HJ (2007) Intradiscal pressure, shear strain, and fiber strain in the intervertebral disc under combined loading. Spine, 32: 748-755.

70. Shine KM, Simson JA, Spector M (2009) Lubricin distribution in the human intervertebral disc. J Bone Joint Surg Am, 91: 2205-2212.

71. Skórzewska A, Grzymisławska M, Bruska M, Lupicka J, Woźniak W (2013) Ossification of the vertebral column in human foetuses: histological and computed tomography studies. Folia Morphol, 72: 230-238.

72. Smith $\sqcup$, Nerurkar NL, Choi KS, Harfe BD, Elliott DM (2011) Degeneration and regeneration of the intervertebral disc: lessons from development. Dis Model Mech, 4: 31-41.

73. Smith CA, Tuan RS (1994) Human PAX gene expression and development of the vertebral column. Clin Orthop Relat Res, 302: $241-250$.

74. Smits P, Lefebvre V (2003) Sox 5 and Sox6 are required for notochord extracellular matrix sheath formation, notochord cell survival and development of the nucleus pulposus of intervertebral discs. Development, 130: 1135-1148.

75. Stemple DL (2005) Structure and function of the notochord: an essential organ for chordate development. Development, 132: 2503-2512.

76. Suseki K, Takahashi Y, Takahashi K, Chiba T, Yamagata M, Moriya $H$ (1998) Sensory nerve fibers from lumbar intervertebral discs pass through rami communicantes. J Bone Joint Surg, 80-B: 737-742.

77. Takahasi Y, Ohtori S, Takahashi K (2009) Peripheral nerve pathways of afferent fibers innervating the lumbar spine in rats. J Pain, 10: 416-425.

78. Taylor JR, Twomey LT (1988) Growth of human intervertebral discs and vertebral bodies. J Anat, 120: 49-68.

79. Tomaszewski KA, Adamek D, Konopka T, Tomaszewska R, Walocha JA (2015) Endplate calcification and cervical intervertebral disc degeneration - the role of end plate marrow contact channel occlusion. Folia Morphol, 74: 84-92.

80. Tomaszewski KA, Adamek D, Pasternak A, Głowacki R, Tomaszewska R, Walocha JA (2014) Degeneration and calcification of the cervical endplate is connected with a decreased expression of ANK, ENPP-1, OPN and TGF- $\beta 1$ in the intervertebral disc. Pol J Pathol, 65: 204-211.

81. Urban JP, Roberts S (2003) Degeneration of the intervertebral disc. Arthritis Res Ther, 5: 120-130.

82. Urban JP, Smith S, Fairbank JC (2004) Nutrition of the intervertebral disc. Spine (Phila Pa 1976), 29: 2700-2709.

83. Verzijl N, DeGroot J, Thorpe SR, Bank RA, Shaw JN, Lyons TJ, Bijlsma JW, Lafeber FP, Baynes JW, TeKoppele JM (2000) Effect of collagen turnover on the accumulation of advanced glycation end products. J Biol Chem, 275: 39027-39031.

84. Videman T, Gibbons LE, Battié MC, Maravilla K, Vanninen E, Leppävuori J, Kaprio J, Peltonen L (2001) The relative roles of intragenic polymorphisms of the vitamin d receptor gene in lumbar spine degeneration and bone density. Spine, 26: E7-E12.

85. Vresilovic EJ, Johannessen W, Elliott DM (2006) Disc mechanics with transendplate partial nucleotomy are not fully restored following cyclic compressive loading and unloaded recovery. J Biomech Eng, 128: 823-829.

86. Wallace AL, Wyatt BC, McCarthy ID, Hughes SPF (1994) Humoral regulation of blood flow in the vertebral endplate. Spine, 19: 1324-1328.

87. Watanabe H, Yamada Y, Kimata K (1998) Roles of aggrecan, a large chondroitin sulfate proteoglycan, in cartilage structure and function. J Biochem (Tokyo), 124: 687-693.

88. Weiler C, Nerlich AG, Zipperer J, Bachmeier BE, Boos N (2002) SSE Award Competition in Basic Sciences: expression of major matrix metalloproteinases is associated with intervertebral disc degeneration and resorption. Eur Spine J, 11: 308-320.

89. Whalen JL, Parke WW, Mazur JM, Stauffer ES (1985) The intrinsic vasculature of developing vertebral end plates and its nutritive significance to the intervertebral discs. J Pediatr Orthop, 5: 403-410.

90. Wiberg G (1947) Back pain in relation to the nerve supply of the intervertebral discs. Acta Orthop Scand, 19: 211-221.

91. Yu J, Fairbank JC, Roberts S, Urban JP (2005) The elastic fibre network of the annulus fibrosus of the normal and scoliotic human intervertebral disc. Spine, 30: 1815-1820. 